\title{
Mapping the Sustainable Development Goals into the EDINSOST Sustainability Map of Bachelor Engineering Degrees
}

\author{
Fermín Sánchez, David López, Ramon Bragós, Jose Cabre, Joan Climent, Eva Vidal, and Carme Martín \\ Universitat Politècnica de Catalunya - BarcelonaTech \\ Barcelona, Spain \\ fermin@ac.upc.edu, david@ac.upc.edu, ramon.bragos@upc.edu, jose.cabre@upc.edu, juan.climent@upc.edu, eva.vidal@upc.edu, \\ martin@essi.upc.edu
}

\begin{abstract}
This Research to Practice Work in Progress paper presents the work conducted on the use of the Sustainability Map of Bachelor Engineering Degrees (a tool developed by the EDINSOST project) to analyze how Sustainable Development Goals (SDGs) are developed in each Degree. Over recent years, there has been a growth in the importance of working sustainability based on the SDGs. To identify which learning objective of each SDG corresponds to each learning outcome of the EDINSOST Sustainability Map, a correspondence matrix has been defined. The matrix contains the learning outcomes of the EDINSOST Sustainability Map in its rows, and the 17 SDGs in the columns. The cells of the matrix contain the learning objectives of the SDGs that correspond to each learning outcome of the EDINSOST Sustainability Map. This work in progress presents the first results of the process of mapping the SDGs into the EDINSOST Sustainability Map of Engineering Bachelor Degrees. Early results show that some of the 169 learning objectives are not applicable to Engineering Degrees. Likewise, we have seen that learning objectives have been defined more for policy makers than for engineers, and therefore adaptation is not an easy task. However, the work done has helped us to verify that the EDINSOST Sustainability Map can help in the introduction of the SDGs into the curriculum.
\end{abstract}

Keywords-sustainability, sustainable development, Sustainability Map, competencies map, ESD, SDGs, EDINSOST.

\section{INTRODUCTION}

As an institution dedicated to the creation and transmission of knowledge through research and teaching, the University plays a leading role in the dissemination and application of possible solutions and alternatives to the socio-environmental problems facing today's society [1, 15, 17]. UNESCO [16] recognizes that education is a key element in the achievement of sustainable development. To advance towards this goal, in 2015 UNESCO defined 17 Sustainable Development Goals (SDGs) that must be reached by 2030 . These objectives should be a priority for all the governments of the planet.

The experiences and learning of the university community are of great importance for the achievement of a change towards the culture of sustainability. In this sense, the integration of Education for Sustainable Development (ESD) in Higher Education contributes to the development by university graduates of sustainability competencies, such as critical and creative thinking; problem solving; capacity for action, collaboration and systemic thinking, thereby training potential agents of change capable of configuring more sustainable societies [2, 3, 4]. Numerous universities have signed international declarations committing them to the introduction of Sustainable Development in their educational policy; including the curriculum, research and social projection $[10$, $11,12,18]$. This is not a question about 'what' to do, but about 'how' to do it. Introducing sustainability in the curriculum implies the empowerment of the university community and the creation of spaces for reflection and collective collaboration, both inter- and trans-disciplinary, to encourage learning, critical reflection on existing practices and worldviews, and creative and innovative action. One of the greatest challenges facing universities in the 21 st century is to promote and improve training to produce critical professionals capable of acting on the principles of sustainability [5, 6, 7]. Several studies show that, despite the efforts made so far, progress in this sense has been slow and insufficient [9].

The integration of sustainability in the curriculum, the design of teaching and learning strategies for its implementation in the Spanish university context, and the assessment of the competencies in sustainability of current graduates, represent the central focus of the EDINSOST project. EDINSOST has the general objective of advancing educational innovation in ESD in Spanish universities to provide future graduates with the necessary skills to catalyze the change towards a more sustainable society.

\section{THE SUSTAINABILITY MAP OF BACHELOR ENGINEERING DEGREES}

The EDINSOST project has focused on designing instruments to evaluate sustainability in Bachelor and Master Degrees in engineering, education, business administration and management, and environmental sciences. A Sustainability Map has been designed for each of these types of degrees. The Sustainability Map is a Competency Map [13] which states what graduates should know on finishing their studies.

A Competency Map is a matrix whose cells contain the learning outcomes (LO) expected of students at the end of the learning process [13]. The rows contain the Competency Units, while the columns indicate the domain levels of the taxonomy 
used to classify the LOs. The taxonomy used in the EDINSOST project is a simplified version of the Miller pyramid [8], as described in [14]. A detailed listing of the LOs of the EDINSOST Sustainability Map on Bachelor Engineering Degrees can be found in [14].

The Sustainability Map of Bachelor Engineering Degrees of the EDINSOST project and the SDGs were published in parallel, so the map does not directly consider the SDGs, although it does take into account all the previous UNESCO documents. Therefore, authors considered it necessary to carry out a work to identify how the Sustainability Map develops each of the SDGs. Should any SDG not be properly developed in the map, the introduction of a new LO on the Sustainability Map should be considered in order to develop it.

Our initial interest was to see whether the Sustainability Map of Bachelor Engineering Degrees was in tune with what the UNESCO proposed to develop sustainability, in order to strengthen the validity of EDINSOST's map.

\section{IDENTIFICATION OF SDGS IN THE SUSTAINABILITY MAP}

Authors are currently undertaking work to relate the SDGs with the LOs of the Sustainability Map of Bachelor Engineering Degrees. Since this work is in process, it is presented in the FIE as a WIP. The UNESCO report [16] has been used as a base document for the SDGs. For each of the 17 SDGs, this report defines 15 learning objectives grouped into three categories. These categories are: "Cognitive learning objectives", "Socio-emotional learning objectives", and "Behavioral learning objectives". Each category contains 5 learning objectives, numbered from 1 to 5 . The objectives of the category "Cognitive learning objectives" correspond, in general, to the LOs of the "know" domain level of the Sustainability Map. The objectives of the category "Socioemotional learning objectives" correspond to the domain levels "Know" and "Know How", and the objectives of the category "Behavioral learning objectives" correspond to the LOs of the "Demonstrated + Do" domain level of the taxonomy.

A matrix has been defined to identify which learning objectives defined by UNESCO correspond to each LO of the Sustainability Map. The matrix contains the LOs of the Sustainability Map in its rows, and the 17 SDGs in the columns. The cells of the matrix contain the UNESCO learning objectives for each SDG that correspond to each LO of the map. To facilitate the identification of the UNESCO learning objectives, they have been renumbered as C1..C5, SE1..SE5 and B1..B5, so that the letter preceding the number identifies the category (cognitive, socio-emotional or behavioral).

When analyzing the leaning objectives defined by UNESCO, we noticed that the 17 SDGs have been developed by different groups of experts. Therefore, although a final unification process exists, not all the learning objectives have been defined with the same granularity. In addition, learning objectives have been defined to be achieved for the whole education system. Some of them must therefore be developed at pre-university levels of education, while others must be developed only in some degrees. Thus, author's task has been to identify which objectives correspond to an Engineering Bachelor Degree.
However, not all engineering degrees must necessarily develop the same objectives, since some degrees are oriented to a particular SDG. Therefore, the Engineering Degrees related to industrial issues will develop SDG6 (Clean water and sanitation), SDG7 (Affordable and clean energy) or SDG9 (Industry, innovation and infrastructure) in a special way. In the same way, other degrees in the university system will have more impact on some particular objectives.

The work that the authors are currently doing is aimed at identifying the learning objectives of the SDGs that correspond (in general) to all the Engineering Degrees. On the basis of this work, each Engineering Degree must select the SDGs directly related to its own field of specialty and add to the map those learning objectives considered as appropriated.

Mapping SDGs on the Sustainability Map of Bachelor Engineering Degrees is not an easy job. The LOs on the map were designed to be generic for all Engineering Degrees, so they generally have a greater granularity than the learning objectives of SDGs. Therefore, usually more than one learning objective (from different SDGs) corresponds to each LO of the map. However, in some cases, we have found learning objectives of such a large granularity that the LO defined on the map is only a small part of the learning objective (although this has not been the general case). Although all the learning objectives should be included in the LO of the Sustainability Map, in a few instances we have found that this is not the case. These learning objectives have therefore been added to the Sustainability Map in order to complete it.

On the other hand, for some learning objectives we have found that the verb used in the definition did not correspond to the domain level of the taxonomy defined in the LO of the Sustainability Map. For example, in some cases the learning objective defined an objective that required "understanding", while the Sustainability Map specified a related LO but belonging to the "Know" domain level (or vice versa).

Finally, some learning objectives refer to other generic competencies, such as the ability to communicate. In these cases, we have not considered the verb (to communicate) but the learning objective to be communicated, in order to decide to which LO of the map the learning objective corresponds.

When it comes to establishing the correspondence between learning objectives and LOs, the correspondence is not one-toone. A certain LO can develop several learning objectives, and in turn the same learning objective can appear in different LOs. This is because the LOs of the Sustainability Map are described in a very generic way, which enables them to be easily adapted to any Engineering Degree.

In order to illustrate everything described above, we will try to show with an example how we have mapped the learning objectives of a given SDG in the Sustainability Map. The example we have selected is SDG9: "Industry, Innovation and Infrastructure". We have selected this SDG because it presents all the possible cases described above. The learning objectives for SDG9, defined in [16], are as follows (textually cited):

"Cognitive learning objectives: 
- C1. The learner understands the concepts of sustainable infrastructure and industrialization and society's needs for a systemic approach to their development.

- C2. The learner understands the local, national and global challenges and conflicts in achieving sustainability in infrastructure and industrialization.

- C3. The learner can define the term resilience in the context of infrastructure and spatial planning, understanding key concepts such as modularity and diversity, and apply it to their local community and nationwide.

- C4. The learner knows the pitfalls of unsustainable industrialization and in contrast knows examples of resilient, inclusive, sustainable industrial development and the need for contingency planning.

- C5. The learner is aware of new opportunities and markets for sustainability innovation, resilient infrastructure and industrial development.

Socio-emotional learning objectives:

- SE1. The learner is able to argue for sustainable, resilient and inclusive infrastructure in their local area.

- SE2. The learner is able to encourage their communities to shift their infrastructure and industrial development toward more resilient and sustainable forms.

- SE3. The learner is able to find collaborators to develop sustainable and contextual industries that respond to our shifting challenges and also to reach new markets.

- SE4. The learner is able to recognize and reflect on their own personal demands on the local infrastructure such as their carbon and water footprints and food miles.

- SE5. The learner is able to understand that with changing resource availability (e. g. peak oil, peak everything) and other external shocks and stresses (e. g. natural hazards, conflicts) their own perspective and demands on infrastructure may need to shift radically regarding availability of renewable energy for ICT, transport options, sanitation options, etc.

Behavioral learning objectives:

- $\quad$ B1. The learner is able to identify opportunities in their own culture and nation for greener and more resilient approaches to infrastructure, understanding their overall benefits for societies, especially with regard to disaster risk reduction.

- B2. The learner is able to evaluate various forms of industrialization and compare their resilience.

- B3. The learner is able to innovate and develop sustainable enterprises to respond to their countries' industrial needs.
- B4. The learner is able to access financial services such as loans or microfinance to support their own enterprises.

- B5. The learner is able to work with decision-makers to improve the uptake of sustainable infrastructure (including internet access)."

The first three learning objectives $(\mathrm{C} 1, \mathrm{C} 2$ and $\mathrm{C} 3)$ have a granularity much greater than the LOs on the EDINSOST Sustainability Map, and are the type of objectives to which each Engineering Degree contributes (if it is the case) in a different way and with a different intensity.

Objective $\mathrm{C} 1$ can be related to the LOs: "Knows technologies of reuse, reduction, recycling and minimization of the natural resources and residues related to a project of the Engineering", and "Knows the life cycle of the products related to the Engineering (construction, use and destruction/ dismantling) and the concept of ecological footprint".

Objective $\mathrm{C} 2$ is related to the following LOs on the EDINSOST Sustainability Map: "Is aware that products and services related to the Engineering have an environmental impact throughout its life", "Takes into account the rights of people in their work as an engineer"; "Understands the need to introduce social justice, equity, diversity, transparency (gender perspective, needs of the most vulnerable groups, anticorruption, etc.) in projects of the Engineering"; "Can assess whether an engineering project contributes to improving the common good of society", and "Is capable of assessing the impact that different products and services related to the Engineering have on society and on the sustainability of the planet".

Objective C3 is developed in LOs "Knows the strategic role that the technologies related with the Engineering play in the sustainability of the planet", and "Is capable of assessing the impact (positive and negative) that different products and services related to the Engineering have on society and on the sustainability of the planet.".

Objectives C4 and C5 can be clearly identified with some LOs on the EDINSOST Sustainability Map, and they are of similar granularity.

Objective C4 is identified with the LOs "Knows the main causes, consequences and solutions proposed in the literature regarding the social, economic and/or environmental problems, both locally and globally"; "Identifies the main causes and consequences of a problem related to the sustainability that a product or a service related to the Engineering can have, and is able to relate them to known problems and solutions previously applied", and "Is capable of assessing the impact that different products and services related to the Engineering have on society and on the sustainability of the planet".

Objective C5 is identified with the LOs "Knows the concept of social economy, the advantages of solidarity, teamwork and cooperation versus competition"; "Knows the principles of the economy for the common good", and "Knows how to assess the economic viability of a project of the Engineering and whether it is compatible with the environmental and social aspects of sustainability. 
With respect to socio-emotional objectives, SE1 refers to communication competency (the verb used is "able to argue"). However, to be able to argue what is indicated in the objective, it is necessary to know and understand the topics indicated. For that reason, we consider that Objective SE1 is related to LOs "Knows the strategic role that the technologies related with the Engineering play in the sustainability of the planet", and "Knows the concept of social economy, the advantages of solidarity, teamwork and cooperation versus competition".

The remaining socio-emotional objectives do not seem to have a direct relationship with Bachelor Engineering Degrees. They should probably be developed at other educational levels or at different university levels rather than Bachelor Degrees. In some cases, we believe that the objectives presented in the UNESCO document (2017) should be developed in some Master Degrees, but not in Bachelor Degrees. This is especially evident in those objectives whose aim is that the student "is able to encourage his or her community to" (SE2) or "work with decision-makers to" (B5).

\section{Regarding Behavioral learning objectives:}

Objective B1 is closely related to the LOs "Identifies the main causes and consequences of a problem related to the sustainability that a product or a service related to the Engineering can have, and is able to relate them to known problems and solutions previously applied", and "Is capable of proposing solutions and strategies to promote projects in the field of the Engineering, consistent with these principles".

Objective B2 is related to the following LOs: "Analyzes the different dimensions of sustainability when solving a specific problem related to the Engineering"; "Calculates the ecological footprint of an Engineering project"; "Includes in his/her projects indicators to estimate/measure these effects from the resources used by the project (e.g. energy consumption, pollutant emissions, consumption of resources, etc.).", "Is capable of assessing the impact (positive and negative) that different products and services related to the Engineering have on society and on the sustainability of the planet"; "Given a project in the field of the Engineering, which includes collaborative community work, is able to assess the implications of such work for the sustainability of the project", and "Is able to assess the implications of the deontological principles related to sustainability in a project in the field of the Engineering".

Objective B3 is a highly important requirement for a Bachelor Degree, but to a lesser extent it can be related to the following LOs of the Sustainability Map: "Brings new ideas and solutions to a project related to the Engineering to make it more sustainable, so as to improve the sustainability of products, processes or services", and "Is capable of proposing solutions and strategies to promote projects in the field of the Engineering, consistent with these principles".

The remaining Behavioral learning objectives do not seem to be directly related to the work expected of a Bachelor Degree student.

\section{CONCLUSIONS}

In this paper, we present the work that the authors are carrying out to relate the learning outcomes of the Sustainability Map of Bachelor Engineering Degrees of the EDINSOST project with the SDG defined by UNESCO in 2015. The Sustainability Map of the Bachelor Engineering Degrees of EDINSOST [14] and the UNESCO document that defines the Learning Objectives of the SDGs [16] are used as the main reference documents.

The Sustainability Map of the Bachelor Engineering Degrees of the EDINSOST project describes learning outcomes very generically, and thus they can easily be adapted to any Engineering Degree, so that each of these learning outcomes can be related to several learning objectives of the UNESCO document.

The detailed analysis of the UNESCO document reveals that the 17 SDGs have not been defined with the same level of granularity, although all of them follow the same scheme: Five Cognitive learning objectives, five Socio-emotional learning objectives and five Behavioral learning objectives. This is probably because each SDG has been commissioned to a small group of experts on the subject, some of whom have identified a greater level of detail for their learning objectives than others. This makes it difficult for all those who wish to implement these objectives in their degrees, but it is undoubtedly a valuable work that represents a first step towards introducing SDGs at all educational levels.

Both the Sustainability Maps of the EDINSOST project and the UNESCO documents are highly valuable tools for educators, since they guide them on the path to achieving an appropriate Education for Sustainable Development. There is no doubt that this type of education is essential for citizens of both the present and the future. Because the future will be sustainable or will not be at all.

The next step will be to readjust the Engineering Sustainability Map of the EDINSOST Project, as far as possible, to the UNESCO learning objectives, and to communicate the detected incongruities.

\section{ACKNOWLEDGMENT}

This work is supported by Ministerio de Economía, Industria y Competitividad, Gobierno de España, grants number EDU2015-65574-R and RTI2018-094982-B-I00.

\section{REFERENCES}

[1] A. Beynaghi, et al. "Future sustainability scenarios for universities: Moving beyond the United Nations Decade of Education for Sustainable Development". Journal of Cleaner Production, 2016, 112: 3464-3478. Doi: https://doi.org/10.1016/j.jclepro.2014.09.052

[2] K. Ceulemans, I. Molderez, and L. Van Liedekerke. "Sustainability reporting in higher education: a comprehensive review of the recent literature and paths for further research". Journal of Cleaner Production, 106, 127-143. 2015. doi.org/10.1016/j.jclepro.2014.09.052

[3] B.J. De Vries, and A.C. Petersen. "Conceptualizing sustainable development: An assessment methodology connecting values, knowledge, worldviews and scenarios". Ecological Economics, 68(4), 1006-1019. 2009. https://doi.org/10.1016/j.ecolecon.2008.11.015 
[4] W. Leal Filho, et al. (ed.). "Implementing Campus Greening Initiatives: Approaches, Methods and Perspectives". Springer, 2015

[5] D. Fischer, et al. "UN Global Action Programme and Education for Sustainable Development: A Critical Appraisal of the Evidence Base", Discourse and Communication for Sustainable Education, 6(1), 5-20. 2015. doi: https://doi.org/10.1515/dcse-2015-0001

[6] J.A. Flagg, and D.C. Bates, D. C. "Recycling as a result of "cultural greening"?". International Journal of Sustainability in Higher Education, 17(4), 489-505. 2015 https://doi.org/10.1108/IJSHE-02-2015-0036

[7] E. Hoover, and M.K. Harder. What lies beneath the surface? The hidden complexities of organizational change for sustainability in higher education. Journal of Cleaner Production, 106, 175-188. 2015. DOI: 10.1016/j.jclepro.2014.01.081

[8] G. E. Miller. "The assessment of clinical skills /competence /performance." Academic medicine 65 (9): S63-S67. 1990.

[9] J. Moore. "Barriers and pathways to creating sustainability education programs: policy, rhetoric and reality". Environmental Education Research, 11(5), 537-555. 2005. Doi: 10.1080/13504620500169692

[10] R. Lozano. "Diffusion of sustainable development in universities' curricula: an empirical example from Cardiff University". J. of Cleaner Production 18(7):637-644 (2010) doi.org/10.1016/j.jclepro.2009.07.005

[11] R. Lozano et al. "A review of commitment and implementation of sustainable development in higher education: results from a worldwide survey". Journal of Cleaner Production, 2015, 108: 1-18. DOI: 10.1016/j.jclepro.2014.09.048

[12] D. O'Byrne, W. Dripps, and K.A. Nicholas. "Teaching and learning sustainability: An assessment of the curriculum content and structure of sustainability degree programs in higher education". Sustainability Science, 10(1), 43-59. 2015. https://doi.org/10.1007/s11625-014-0251-y

[13] F. Sánchez Carracedo, A. Soler, C. Martín, D. López, A. Ageno, J. Cabré, J. García, J. Aranda, and K. Gibert. "Competency Maps: an Effective Model to Integrate Professional Competencies Across a STEM Curriculum". Journal of Science Education and Technology, 27(5), 2018, pp. 448-468. DOI 10.1007/s10956-018-9735-3.

[14] F. Sánchez Carracedo, J. Segalàs, E. Vidal, C. Martin, J. Climent, D. López, and J. Cabré. "Improving Engineering Educators' Sustainability Competencies by using Competency Maps. The EDINSOST Project". International Journal in Engineering Education, Vol. 34, No. 5, pp. $1527-1537,2018$.

[15] UNESCO (2005). "United Nations Decade of Education for Sustainable Development (2005-2014): Draft International Implementation Scheme". Available at: http://unesdoc.unesco.org/images/0014/001416/141629e.pdf. Accessed 18 march 2019.

[16] UNESCO 2017. "Education for Sustainable Development Goals. Learning Objectives". Available at: https://unesdoc.unesco.org/ark:/48223/pf0000247444. Accessed 18 march 2019.

[17] United Nations. (2012). "The future we want: Outcome document adopted at Rio+20". Available at: https://sustainabledevelopment.un.org/content/documents/733FutureWe Want.pdf. Accessed 18 march 2019.

[18] T. S. A. Wright. "University presidents' conceptualizations of sustainability in higher education". International Journal of Sustainability in Higher Education, 11(1), 61-73. 2010. https://doi.org/10.1108/14676371011010057 